\title{
A Painless Thoracic Aortic Dissection
}

\author{
Youssef Mahmoud ${ }^{1}$, Tamer Shalaby $^{2}$, Nazia Rashid ${ }^{3}$
}

${ }^{1}$ SHO General Internal Medicine, Ashford and St Peter's NHS Trust, Ashford, United Kingdom

2ST7 Acute and General Internal Medicine HEKSS, Ashford and St Peter's NHS Trust, Ashford, United Kingdom

${ }^{3}$ Consultant Diabetes, Endocrinology and Acute Medicine, Ashford and St Peter's NHS Trust, Ashford, United Kingdom

Received: 26/05/2016

Accepted: $13 / 06 / 2016$

Published: $27 / 07 / 2016$

How to cite this article: Mahmoud Y, Shalaby T, Rashid N. A painless thoracic aortic dissection. EJCRIM 2016;3:doi:10.12890/2016 000443.

Conflicts of Interests: The Authors declare that there are no competing interests.

This article is licensed under a Commons Attribution Non-Commercial 4.0 License

\section{ABSTRACT}

Thoracic aortic dissection (TAD) has a very high mortality rate and is often missed due to the atypical presentation of patients. We present a case of a man with chronic hypertension, atrial fibrillation (AF) (on regular warfarin) and a previous endovascular aneurysm repair (EVAR), who presented with dyspepsia and was incidentally found to have a ruptured distal thoracic aneurysm on imaging with no obvious clinical signs on examination, nor abnormalities on admission chest $x$-ray (CXR).

\section{LEARNING POINTS}

- Typical symptoms and signs of thoracic aortic dissection (TAD), such as sudden onset of tearing pain and difference in blood pressure, can be absent in patients.

- Clinicians should consider imaging of the aorta in high-risk patients who present with syncope, focal neurology and/or atypical chest, back or abdominal pain.

- There may be a role for D-dimer in the future to rule out the possibility of TAD, similar to pulmonary embolism (PE).

\section{KEYWORDS}

Thoracic aortic dissection, CT aortogram, D-dimer, EVAR.

\section{CASE DESCRIPTION}

A 79-year-old male with a background of hypertension, atrial fibrillation (AF), chronic lymphocytic leukemia (CLL) and endovascular aneurysm repair (EVAR) of bilateral common iliac artery aneurysm (performed one year prior) was admitted to Accident and Emergency department with a progressively worsening burning sensation in epigastrium, associated with burping, which started a month prior to admission.

The patient had recently seen a general practitioner (GP), who prescribed omeprazole for gastro-oesophageal reflux disease (GORD).

On examination, the patient was pain free, with occasional burping. His chest was clear on auscultation, with no signs of respiratory distress. He was hemodynamically stable and alert, with no focal neurological abnormality. His abdomen was soft and non-tender, with no pulsatile mass. His calves were non-tender, and distal pulsations were felt and equal.

Investigations: electrocardiography (ECG) on admission and repeated at 5 hours were unremarkable. Troponins on admission and after 12 hours were normal. Admission chest X-ray (CXR) did not show significant abnormality. However, D-Dimers were high on admission. Random blood tests showed normocytic chronic anaemia; haemoglobin of 102; and an international normalized ratio (INR) of 3 , as the patient was on warfarin. Urine dip showed trace blood and protein. 
Methods and Procedures: based on the initial clinical examination and investigations, the impression was likely GORD. The patient was treated with intravenous (IV) pantoprazole and booked for an oesophago-gastro duodenoscopy (OGD). In view of raised D-Dimer and epigastric discomfort, a CT pulmonary angiogram (CTPA) was done (Fig. 1), which revealed an incidental finding of rupture/intramural hematoma/ dissection of the descending thoracic aorta. Therefore, we proceeded with an urgent computed tomography (CT) angiogram of the aorta (Figs. 2 and 3), which confirmed the presence of a contained rupture involving the descending thoracic aorta. The patient was urgently referred to vascular surgery. IV Labetalol was administered to keep systolic blood pressure below 120; vitamin K and prothrombin complex concentrate were administered to reverse INR; finally, no analgesia was required as the patient was surprisingly pain free.

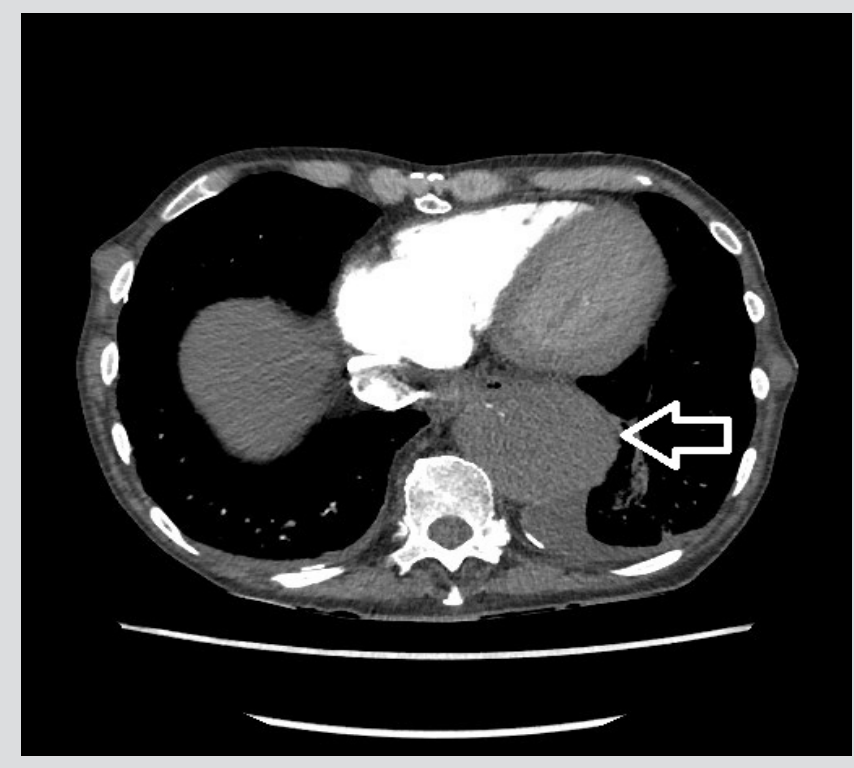

Figure 1. CTPA (cross-section)

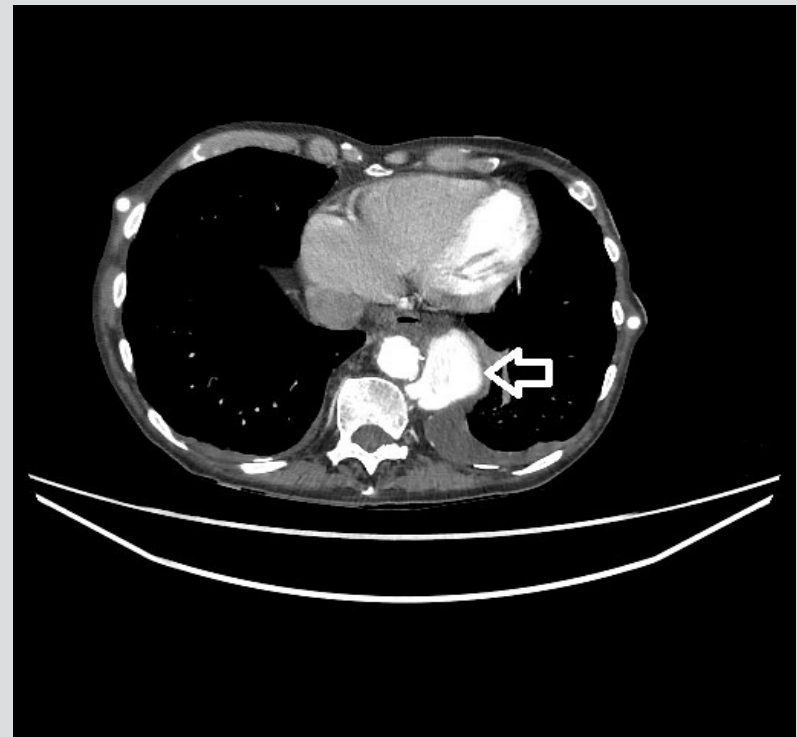

Figure 2. CT Angiogram of the aorta (cross-section)

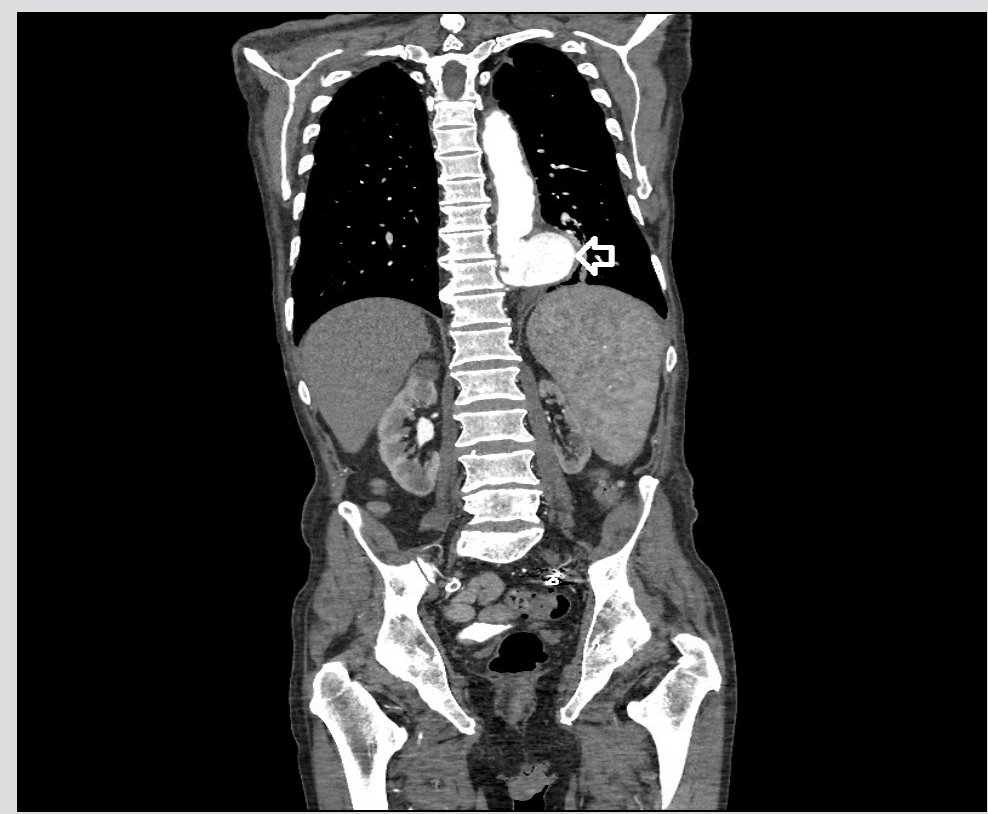

Figure 3. CT Angiogram of the aorta (coronal section) 


\section{DISCUSSION}

There are numerous diseases/conditions associated with aortic dissection (Table 1$)^{[4]}$. Once a dissection occurs, it can propagate and involve other branches of the aorta ${ }^{[3,4]}$. TAD is classified according to anatomical location: Stanford type A involves the ascending aorta, and Stanford type B occurs distal to the left subclavian artery ${ }^{[1-4]}$.

Clinical Features: TAD often presents with atypical symptoms and signs and, thus, a very high level of suspicion in patients with risk factors is required to determine the diagnosis. The most common clinical presentations are the following:

1. Pain, usually of an abrupt onset anterior chest pain in type A dissection, while in type B the pain is mainly in the abdomen and/or the back. Most patients describe it as a sharp pain, rather than a tearing pain. TAD can be absolutely painless in up to $4.5 \%$ of patients ${ }^{[4,5]}$;

2. Syncope, which can be associated with severe pain from dissection or can be painless secondary to cardiac tamponade or cerebral hypoperfusion ${ }^{[4,5]}$;

3. Acute neurological signs, which occur frequently with TAD, and careful examination of peripheral pulses may help with the diagnosis, which can be confirmed by CT angiogram involving carotids, ascending aorta and aortic arch ${ }^{[6,7]}$;

4. Anuric acute renal failure or acute abdomen can be the presenting feature in TAD progressing distally and involving renal and mesenteric arteries respectively ${ }^{[5,8]}$;

5. Pulse deficit between both arms or aortic regurge murmur, which were thought to be typical clinical signs of TAD, are often absent, and only 1 in 4 patients in one study presented with hypertension ${ }^{[4,5,8]}$.

Investigations: CXR can show mediastinal widening, abnormal aortic contour or pleural effusion, however, most times, it is unremarkable. Electrocardiogram (ECG) can show non-specific changes or be entirely normal ${ }^{[4,5,8]}$. Transthoracic echocardiography (TTE) reliably identifies complications of TAD, such as pericardial effusion and aortic regurgitation, and helps in evaluating alternative diagnoses. Additionally, an intimal flap at either the aortic root or descending aorta may be distinguished by TTE and is diagnosti ${ }^{[12]}$. Therefore, routine TTE may be a useful screening tool for TAD.

Positive plasma D-dimer is non-specific, however a negative plasma D-dimer can be a useful screening tool to rule out TAD, as shown in a meta-analysis study by Shimony A et al..$^{[9]}$. Troponin can be normal, as in our case, however a raised troponin can be related to myocardial infarction secondary to coronary ostial occlusion.

CT aortogram has average sensitivity that exceeds $95 \%$, with specifity that ranges from 85 to $100 \%$. This is useful in emergency settings and available 24 hours a day, compared to MRI and Transesophageal Echo (TEE), and can be more accurate in detecting aortic arch vessel involvement ${ }^{[10,11]}$.

Treatment: TAD type $A$ is a surgical emergency, while uncomplicated type $B$ at present is best treated with medical therapy that includes IV Beta blockers, like Labetalol, to reduce systolic blood pressure to below 120. Indications for endovascular interventions in type B TAD are persistent pain, aortic expansion, dissection progression and end-organ ischemia.

\section{CONCLUSION}

TAD can present with atypical symptoms and signs, therefore we recommend a low threshold to scan high-risk patients who present with syncope, focal neurology and atypical chest, back or abdominal pain. Additionally, a negative plasma D-dimer may play a role in ruling out this diagnosis.

\begin{tabular}{|l|l|}
\hline Long-standing arterial hypertension & $\begin{array}{l}\text { Vascular inflammation } \\
\end{array}$ \\
& $\begin{array}{l}\text { Giant cell arteritis } \\
\text { - Takayasu arteritis } \\
\text { Sehcet's disease }\end{array}$ \\
\hline Smoking, dyslipidemia, cocaine/crack & $\begin{array}{l}\text { Deceleration trauma } \\
\text { - Car accident }\end{array}$ \\
\hline Connective tissue disorders & $\begin{array}{l}\text { latrogenic factors } \\
\text { - Catheter/instrument intervention }\end{array}$ \\
\hline $\begin{array}{l}\text { Hereditary vascular disease } \\
\text { Marfan syndrome }\end{array}$ & \\
\hline$\quad$ Vascular Ehlers-Danlos syndrome (type 4) & \\
\hline$\quad$ Coarctation of the aorta & \\
\hline
\end{tabular}




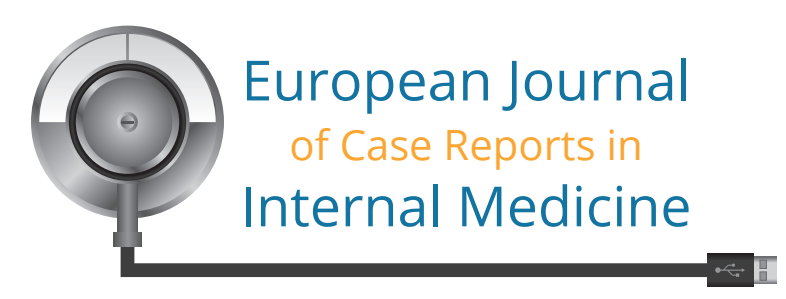

\section{REFERENCES}

1. Meszaros I, Mórocz J, Szlávi J, Schmidt J, Tornóci L et al. Epidemiology and clinicopathology of aortic dissection. Chest 2000;117:1271-1278.

2. Bickerstaff LK, Pairolero PC, Hollier LH, Melton LJ, Van Peenen HJ et al. Thoracic aortic aneurysms: a population-based study. Surgery $1982 ; 92: 1103-1108$.

3. Clouse WD, Hallett JW Jr, Schaff HV, Spittell PC, Rowland CM et al. Acute aortic dissection: population-based incidence compared with degenerative aortic aneurysm rupture. Mayo Clin Proc 2004;79:176-180.

4. Tsai TT, Nienaber CA, Eagle KA. Contemporary Reviews in Cardiovascular Medicine. Acute Aortic Syndromes. Circulation 2005;112:3802-3813.

5. Hagan PG, Nienaber CA, Isselbacher EM, Bruckman D, Karavite DJ et al. The International Registry of Acute Aortic Dissection (IRAD): new insights into an old disease. JAMA 2000;283:897-903

6. Gerber O, Heyer GE, Vieux H. Painless dissections of the aorta presenting as acute neurologic syndromes. Stroke 1986;17:644-7.

7. Veyssier-Belot C, Cohen A, Rougemont D, Levy C, Amarenco P et al. Cerebral infarction due to painless thoracic aortic and common carotid artery dissections. Stroke 1993;24:2111-2113.

8. Nienaber CA, Eagle KA. Aortic Dissection: New Frontiers in Diagnosis and Management. Circulation 2003;108:628-635.

9. Shimony A, Fillon KB, Mottillo S, Dourian T et al. Meta-analysis of usefulness of d-dimer to diagnose acute aortic dissection. Am J Cardiol 2011;107:1227-34.

10. Sommer T, Feshke W, Holzknecht N, Smekal AV, Keller E et al. Aortic dissection: a comparative study of diagnosis with spiral CT, multiplanar transesophageal echocardiography, and MR imaging. Radiology 1996;199:347-452.

11. Ince H, Neinaber CA. Diagnosis and management of patients with aortic dissection. Heart 2007;93:266-270.

12. Strayer RJ, Shearer PL, Hermann LK. Screening, Evaluation, and Early Management of Acute Aortic Dissection in the ED. Curr Cardiol Rev 2012;8:152-7. 